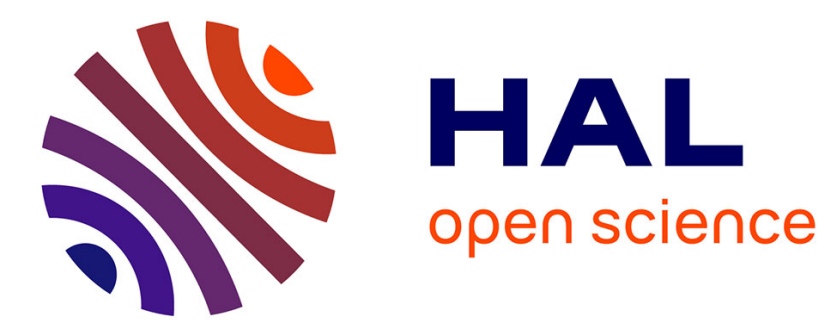

\title{
Procurement Decisions in Multi-period Supply Chain
}

\author{
Izabela Nielsen, Subrata Saha
}

\section{To cite this version:}

Izabela Nielsen, Subrata Saha. Procurement Decisions in Multi-period Supply Chain. IFIP International Conference on Advances in Production Management Systems (APMS), Aug 2018, Seoul, South Korea. pp.433-442, 10.1007/978-3-319-99704-9_53 . hal-02164845

\section{HAL Id: hal-02164845 \\ https://hal.inria.fr/hal-02164845}

Submitted on 25 Jun 2019

HAL is a multi-disciplinary open access archive for the deposit and dissemination of scientific research documents, whether they are published or not. The documents may come from teaching and research institutions in France or abroad, or from public or private research centers.
L'archive ouverte pluridisciplinaire HAL, est destinée au dépôt et à la diffusion de documents scientifiques de niveau recherche, publiés ou non, émanant des établissements d'enseignement et de recherche français ou étrangers, des laboratoires publics ou privés. 


\title{
Procurement decisions in multi-period supply chain
}

\author{
Izabela Nielsen ${ }^{1[0000-0002-3506-2741]}$ and Subrata Saha ${ }^{20000-0002-5118-1548]}$ \\ 1 Department of Materials and Production, Aalborg University, DK 9220 Aalborg, \\ Denmark izabela@mp.aau.dk \\ 2 subrata.scm@gmail.com
}

\begin{abstract}
Pricing and ordering decision in multi-period supply chain environments is not explored comprehensively. We consider three pragmatic procurement scenarios where the retailer can procure products (i) by maintaining strategic inventory, (ii) in bulk in first-period and distribute them in forthcoming selling period, and (iii) without maintaining any inventory. The results suggest that conventional single period planning exhibit sub-optimal characteristics. Build-up strategic inventory is not always profitable for the retailer. The retailer can also earn more profits by employing a bulk procurement strategy.
\end{abstract}

Keywords: Multi-period supply chain · Inventory · Game theory.

\section{Introduction}

Efficient inventory management is one of the key issues in retailing. Retailers maintain inventory to reduce transportation cost, take advantage of quantity discounts, ensure continuity of selling activities, evade variations in wholesale price and demand etc. ( [4], [8], [9]). However, Anand et al. [1] reported that retailer's decision to maintain inventory in multi-period supply chain interactions under manufacturer-stackelberg game can reduce the degree of double marginalization. They found that the retailer can force the manufacturer to reduce the wholesale price of forthcoming periods by maintaining surplus order quantities as strategic inventory. Arya and Mittendorf [3] proved that the manufacturer can curtail advantage of the retailer in building strategic inventory by introducing consumer rebate. Consumer rebate prevents the retailer to maintain high amounts of SI. Arya et al. [2] extended this enticing stream of research and compare the effect of SI in the presence of multiple retail outlets. Hartwig et al. [5] conducted empirical investment to explore the effect of SI and found that the retailer can immensely induce differentiated wholesale pricing behaviour by building up SI. Mantin and Jiang [6] explored the impact of the product quality deterioration in the presence of SI. Moon et al. [7] analyzed the impact of SI in perspective of supply chain coordination. They found that the optimal supply chain profit cannot be achieved by implementing quadratic quantity discount contract mechanism. All the above cited contributions consider multi-period interaction among supply chain member to explore the consequences of SI.

In the existing literature on supply chain models, it is assumed that the retailer procures products to satisfy demand in each selling period. However, in practice, the retailer maintains SI to satisfy future demand. But, to the best of the authors' knowledge, the advantage of SI is not fully explored in current state. We consider three procurement decision for the retailer and explore the 
pricing and ordering behaviour under five consecutive selling period. It is found that the pricing behaviour is correlated with procurement decision. The singleperiod procurement decision always leads to suboptimal solution. The supply chain members can receive higher profit if the retailer maintains SI or procures in bulk.

\section{Problem description}

We explore the interaction in a serial supply chain with one retailer and one supplier under price-sensitive demand in a fifth-period game. The retailer in the supply chain has a downstream retail monopoly and rely solely on the upstream supplier for the retailed good. Three procurement strategies are considered. In first procurement strategy (WSI), the retailer may maintain SI in between twoconsecutive selling period. In Second procurement strategy (BP), the retailer procures in bulk for the first selling period and distribute those in forthcoming periods. Third procurement strategy (BM) is similar to the conventional literature, where the retailer procures products to satisfy demand for each period. We consider linear price sensitive demand and derive optimal solution. For feasibility of the optimal solution, it is assumed that the retail $\left(p_{t}\right)$ and wholesale prices $\left(w_{t}\right)$ at each period satisfy the following relations $p_{t}>w_{t}>0, \forall t=1, \ldots ., 5$. The unit holding cost for the retailer is $h$. All the parameters related to market demand are common knowledge between supply chain members [5].

\subsection{Optimal decision in the presence of SI}

At the beginning of each period $(t=1, \cdots, 5)$, the supplier determines a wholesale price $\left(w_{t}^{w s i}\right)$. The retailer then procures $\left(Q_{t}^{w s i}\right)$ amounts of product and sets retail price $\left(p_{t}^{w s i}\right)$ to satisfy market demand $\left(q_{t}^{w s i}=a-b p_{t}^{w s i}\right)$. If the procured quantity at each period is larger than the quantity sold in the that period (i.e., if $\left.Q_{t}^{w s i}>q_{t}^{w s i}\right)$, then the retailer builds up SI $\left(I_{t}^{w s i}=Q_{t}^{w s i}-q_{t}^{w s i}\right)$ to be sold in the immediate period and invests $h I_{t}^{w s i}$ as holding cost. The profit functions for the supplier and retailer are obtained as follows:

$$
\begin{gathered}
\pi_{r 5}^{w s i}=p_{5}^{w s i}\left(a-b p_{5}^{w s i}\right)-w_{5}^{w s i}\left(a-b p_{5}^{w s i}-I_{4}^{w s i}\right) \\
\pi_{m 5}^{w s i}=w_{5}^{w s i}\left(a-b p_{5}^{w s i}-I_{4}^{w s i}\right) \\
\pi_{r 4}^{w s i}=p_{4}^{w s i}\left(a-b p_{4}^{w s i}\right)-w_{4}^{w s i}\left(a-b p_{4}^{w s i}+I_{4}^{w s i}-I_{3}^{w s i}\right)-h I_{4}^{w s i}+\pi_{r 5}^{w s i} \\
\pi_{m 4}^{w s i}=w_{4}^{w s i}\left(a-b p_{4}^{w s i}+I_{4}^{w s i}-I_{3}^{w s i}\right)+\pi_{m 5}^{w s i} \\
\pi_{r 3}^{w s i}=p_{3}^{w s i}\left(a-b p_{3}^{w s i}\right)-w_{3}^{w s i}\left(a-b p_{3}^{w s i}+I_{3}^{w s i}-I_{2}^{w s i}\right)-h I_{3}^{w s i}+\pi_{r 4}^{w s i} \\
\pi_{m 3}^{w s i}=w_{3}^{w s i}\left(a-b p_{3}^{w s i}+I_{3}^{w s i}-I 2^{w s i}\right)+\pi_{m 4}^{w s i} \\
\pi_{r 2}^{w s i}=p_{2}^{w s i}\left(a-b p_{2}^{w s i}\right)-w_{2}^{w s i}\left(a-b p_{2}^{w s i}-I_{1}^{w s i}+I_{2}^{w s i}\right)+\pi_{r 3}^{w s i}-h I_{2}^{w s i} \\
\pi_{m 2}^{w s i}=w_{2}^{w s i}\left(a-b p_{2}^{w s i}-I_{1}^{w s i}+I_{2}^{w s i}\right)+\pi_{m 3}^{w s i} \\
\pi_{r 1}^{w s i}=p_{1}^{w s i}\left(a-b p_{1}^{w s i}\right)-w_{1}^{w s i}\left(a-b p_{1}^{w s i}+I_{1}^{w s i}\right)-h I_{1}^{w s i}+\pi_{r 2}^{w s i} \\
\pi_{m 1}^{w s i}=w_{1}^{w s i}\left(a-b p_{1}^{w s i}+I_{1}^{w s i}\right)+\pi_{m 2}^{w s i}
\end{gathered}
$$

The optimal solution for the retailer fifth-period optimization problem presented in the first equation is obtained by solving $\frac{d \pi_{r 5}^{w s i}}{d p_{5}^{w s i}}=0$. On simplification, we have $p_{5}^{w s i}=\frac{a+b w_{5}^{w s i}}{2 b}$. The optimal solution for the supplier fifth-period optimization problem presented in the second equation is obtained by solving $\frac{\partial \pi_{m 5}^{w s i}}{\partial w_{5}^{w s i}}=0$. On simplification, one can obtain $w_{5}^{w s i}=\frac{a-2 I_{4}^{w s i}}{2 b}$. The profit function for the retailer and supplier in fifth-period is concave because $\frac{d^{2} \pi_{r 5}^{w s i}}{d p_{5}^{w s i^{2}}}=-2 b<0$ and $\frac{d^{2} \pi_{m 5}^{w s i}}{d w_{5}^{w s i 2}}=-b<0$, respectively.

Substituting the optimal response obtained in fifth-period, profit function for 
the retailer in fourth-period is obtained as follows:

$$
\pi_{r 4}^{w s i}=\frac{a^{2}+12 a I_{4}^{w s i}-12 I_{4}^{w s i 2}}{16 b}+p_{4}^{w s i}\left(a-b p_{4}^{w s i}\right)-\left(a-I_{3}^{w s i}-b p_{4}^{w s i}\right) w_{4}^{w s i}-h I_{4}^{w s i}
$$

The optimal solution for the above problem is obtained by solving $\frac{\partial \pi_{r 4}^{w s i}}{\partial p_{4}^{w s i}}=0$ and $\frac{\partial \pi_{r 4}^{w s i}}{\partial I_{4}^{w s i}}=0$. On simplification, $p_{4}^{w s i}=\frac{a+b w_{4}^{w s i}}{2 b}$ and $I_{4}^{w s i}=\frac{\left.3 a-4 b\left(h+w_{4}^{w s i}\right)\right)}{6}$. Substituting optimal response, the profit function for the supplier is obtained as $\pi_{m 4}^{w s i}=\left(a-I_{3}^{w s i}\right) w_{4}^{w s i}+\frac{b\left(4 h^{2}-4 h w_{4}^{w s i}-17 w_{4}^{w s i^{2}}\right)}{18}$. After solving first order condition, the wholesale price for the fourth period is obtained as $w_{4}^{w s i}=\frac{9 a-2 b h-9 I_{3}^{w s i}}{17 b}$.

Because $\frac{\partial^{2} \pi_{r 4}^{w s i}}{\partial p_{4}^{w s i 2}}=-2 b<0$ and $\frac{\partial^{2} \pi_{r 4}^{w s i}}{\partial p_{4}^{w s i^{2}}} \frac{\partial^{2} \pi_{r 4}^{w s i}}{\partial I_{4}^{w s i^{2}}}-\left(\frac{\partial^{2} \pi_{r 4}^{w s i}}{\partial I_{4}^{w s i} \partial p_{4}^{w s i}}\right)^{2}=3>0$; and $\frac{\partial^{2} \pi_{m 4}^{w s i}}{\partial w_{4}^{w s i 2}}=-\frac{17 b}{9}<0$, the profit function of the retailer and supplier are concave. Similarly, the profit function for the retailer in third-period is obtained as follows:

$$
\begin{aligned}
& \quad \pi_{r 3}^{w s i}=\frac{155 a^{2}-118 a b h+304 b^{2} h^{2}+846 a I_{3}^{w s i}-460 b h I_{3}^{w s i}-423 I_{3}^{w s i} 2}{1156 b} \\
& +p_{3}^{w s i}\left(a-b p_{3}^{w s i}\right)-\left(a-I_{2}^{w s i}+I_{3}^{w s i}-b p_{3}^{w s i}\right) w_{3}^{w s i}-h I_{3}^{w s i}
\end{aligned}
$$

Corresponding optimal retail price and SI are $p_{3}^{w s i}=\frac{a+b w_{3}^{w s i}}{2 b}$ and $I_{3}^{w s i}=$ $\frac{423 a-2 b\left(404 h+289 w_{3}^{w s i}\right)}{423}$, respectively. Substituting optimal response for the retailer, profit function for the supplier in third-period is obtained as follows:

$$
\pi_{m 3}^{w s i}=\frac{3 a w_{3}^{w s i}-2 I_{2}^{w s i} w_{3}^{w s i}}{2}+\frac{b\left(38824 h^{2}-27400 h w_{3}^{w s i}-54561 w_{3}^{w s i}\right)}{39762}
$$

and corresponding wholesale price is $w_{3}^{w s i}=\frac{59643 a-27400 b h-39762 I_{2}^{w s i}}{109122 b}$. Note the the third-period optimization problem for the retailer and supplier are concave because $\frac{\partial^{2} \pi_{r 3}^{w s i}}{\partial p_{3}^{w s i 2}}=-2 b<0$ and $\frac{\partial^{2} \pi_{r 3}^{w s i}}{\partial p_{3}^{w s i 2}} \frac{\partial^{2} \pi_{r 3}^{w s i}}{\partial I_{3}^{w s i 2}}-\left(\frac{\partial^{2} \pi_{r 3}^{w s i}}{\partial I_{3}^{w s i} \partial p_{3}^{w s i}}\right)^{2}=\frac{423}{289}>0$; and $\frac{\partial^{2} \pi_{m 3}^{w s i}}{\partial w_{3}^{w s i^{2}}}=-\frac{18187 b}{6627}<0$. The second-period profit function for the retailer is obtained as follows:

$$
\begin{gathered}
\pi_{r 2}^{w s i}=p_{2}^{w s i}\left(a-b p_{2}^{w s i}\right)-\left(a-I_{1}^{w s i}+I_{2}^{w s i}-b p_{2}^{w s i}\right) w_{2}^{w s i}-h I_{2}^{w s i}+ \\
\frac{0.208932 a^{2}-0.335467 a b h+1.17731 b^{2} h^{2}+0.721424 a I_{2}^{w s i}-0.776356 b h I_{2}^{w s i}-0.240475 I_{2}^{w s i 2}}{b}
\end{gathered}
$$

Corresponding optimal retail price and SI are $p_{2}^{w s i}=\frac{a+b w_{2}^{w s i}}{2 b}$ and $I_{2}^{w s i}=$ $\frac{3 a}{2}-\frac{2 b\left(5288037907 h+2976902721 w_{2}^{w s i}\right)}{2863480311}$, respectively. Substituting optimal response, the profit function for the supplier in second-period is obtained as $\pi_{m 2}^{w s i}=2 a w_{2}^{w s i}$ $I_{1}^{w s i} w_{2}^{w s i}+b\left(2.62087 h^{2}-1.41726 h w_{2}^{w s i}-1.79158 w_{2}^{w s i^{2}}\right)$, and corresponding wholesale price is $w_{2}^{w s i}=\frac{0.558166 a-0.395535 b h-0.279083 I_{1}^{w s i}}{b}$. Note the the second-period optimization problem for the retailer and supplier are concave because $\frac{\partial^{2} \pi_{r 2}^{w s i}}{\partial p_{2}^{w s i^{2}}}=$ $-2 b<0$ and $\frac{\partial^{2} \pi_{r 2}^{w s i}}{\partial p_{2}^{w s i 2}} \frac{\partial^{2} \pi_{r 2}^{w s i}}{\partial I_{2}^{w s i 2}}-\left(\frac{\partial^{2} \pi_{r 2}^{w s i}}{\partial I_{2}^{w s i} \partial p_{2}^{w s i}}\right)^{2}=0.961899>0 ;$ and $\frac{\partial^{2} \pi_{m 2}^{w s i}}{\partial w_{2}^{w s i^{2}}}=$ $-3.58316 b<0$, respectively. Finally, the first-period profit function for the retailer is obtained as follows:

$\pi_{r 1}^{w s i}=\frac{1}{b}\left[0.285445 a^{2}-b I_{1}^{w s i}\left(2.1416 h+w_{1}^{w s i}\right)+a b\left(p_{1}^{w s i}-w_{1}^{w s i}-0.716806 h\right)\right.$

$$
\left.+0.714555 a I_{1}^{w s i}-0.178639 I_{1}^{w s i^{2}}+b^{2}\left(3.19862 h^{2}-p_{1}^{w s i}\left(p_{1}^{w s i}-w_{1}^{w s i}\right)\right)\right]
$$

Correspondingly optimal retail price and SI are $p_{1}^{w s i}=\frac{a+b w_{1}^{w s i}}{2 b}$ and $I_{1}^{w s i}=$ $2 a-5.99421 b h-2.79895 b w_{1}^{w s i}$. Substituting the optimal response for the re- 
tailer, the profit function for the supplier in first-period is obtained as follows:

$$
\pi_{m 1}^{w s i}=2.5 a w_{1}^{w s i}+b\left(5.54404 h^{2}-2.41898 h w_{1}^{w s i}-2.20576 w_{1}^{w s i^{2}}\right)
$$

and corresponding wholesale price is $w_{1}^{w s i}=\frac{0.566697 a-0.548333 b h}{b}$. Note that the first-period optimization problem for the retailer and supplier are concave as $\frac{\partial^{2} \pi_{r 1}^{w s i}}{\partial p_{1}^{w s i^{2}}}=-2 b<0$ and $\frac{\partial^{2} \pi_{r 1}^{w s i}}{\partial p_{1}^{w s i^{2}}} \frac{\partial^{2} \pi_{r 1}^{w s i}}{\partial I_{1}^{w s i^{2}}}-\left(\frac{\partial^{2} \pi_{r 1}^{w s i}}{\partial I_{1}^{w s i} \partial p_{1}^{w s i}}\right)^{2}=0.714555>0$; and $\frac{\partial^{2} \pi_{m 1}^{w s i}}{\partial w_{1}^{w s i^{2}}}=-4.41153 b<0$, respectively. By using back substitution, one can obtain the following optimal solutions:

$$
\begin{gathered}
w_{1}^{w s i}=\frac{0.783349 a-0.274166 b h}{b} w_{2}^{w s i}=\frac{0.442669 a+0.849025 b h}{b} w_{3}^{w s i}=\frac{0.335378 a+1.73797 b h}{b} \\
w_{4}^{w s i}=\frac{0.242614 a+2.15087 b h}{b} w_{5}^{w s i}=\frac{0.161743 a+2.10058 b h}{b} \\
p_{1}^{w s i}=\frac{0.783349 a-0.274166 b h}{b} p_{2}^{w s i}=\frac{0.721334 a+0.424512 b h}{b} p_{3}^{w s i}=\frac{0.667689 a+0.868984 b h}{b} \\
p_{4}^{w s i}=\frac{0.621307 a+1.07544 b h}{b} p_{5}^{w s i}=\frac{0.580871 a+1.05029 b h}{b} \\
I_{1}^{w s i}=0.413846 a-4.45946 b h I_{2}^{w s i}=0.579595 a-5.45874 b h \\
I_{3}^{w s i}=0.541729 a-4.28498 b h I_{4}^{w s i}=0.338257 a-2.10058 b h \\
b_{r 5}^{w s i}=\frac{0.230379 a^{2}-0.509631 a b h-3.30933 b^{2} h^{2}}{b^{2}} \pi_{m 5}^{w s i}=\frac{2.20622(0.0769991 a+b h)^{2}}{b^{2}} \\
\pi_{r 4}^{w s i}=\frac{0.423153 a^{2}-1.75473 a b h-4.75054 b^{2} h^{2}}{b^{2}} \pi_{m 4}^{w s i}=\frac{0.0555915 a^{2}+0.985682 a b h+4.59145 b^{2} h^{2}}{b^{2}} \\
\pi_{r 3}^{w s i}=\frac{0.546283 a^{2}-3.20185 a b h-1.7504 b^{2} h^{2}}{b^{2}} \pi_{m 3}^{w s i}=\frac{0.154342 a^{2}+1.59964 a b h+5.12115 b^{2} h^{2}}{b^{2}} \\
\pi_{r 2}^{w s i}=\frac{0.550566 a^{2}-3.71641 a b h+4.73697 b^{2} h^{2}}{b^{2}} \pi_{m 2}^{w s i}=\frac{0.35107 a^{2}+1.34668 a b h+3.91231 b^{2} h^{2}}{b^{2}} \\
\pi_{r 1}^{w s i}=\frac{0.362978 a^{2}-1.25738 a b h+6.82633 b^{2} h^{2}}{b^{2}} \pi_{m 1}^{w s i}=\frac{0.708371 a^{2}-1.37083 a b h+6.20725 b^{2} h^{2}}{b^{2}} .
\end{gathered}
$$

\subsection{Optimal decisions in Scenario BP}

At the beginning of first period, the supplier determines a wholesale price $\left(w_{1}^{b p}\right)$ and then the retailer procures $a-b p_{1}^{b p}+\sum_{t=1}^{4} I_{t}^{b p}$ unit of products and sets the retail price $\left(p_{1}^{b p}\right)$. In next four selling period, the supplier determines wholesale price $\left(w_{t}^{b p}\right)$ and then the retailer procures $\left(q_{t}^{b p}=a-b p_{t}^{b p}-I_{t-1}^{b p}\right)(t=2, \cdots, 5)$ units of product and sets retail price $\left(p_{t}^{b p}\right)$ to satisfy market demand. The profit functions of the supplier and retailer for five consecutive selling periods are obtained as follows:

$$
\begin{gathered}
\pi_{r 5}^{b p}=p_{5}^{b p}\left(a-b p_{5}^{b p}\right)-w_{5}^{b p}\left(a-b p_{5}^{b p}-I_{4}^{b p}\right) \\
\pi_{m 5}^{b p}=w_{5}^{b p}\left(a-b p_{5}^{b p}-I_{4}^{b p}\right) \\
\pi_{r 4}^{b p}=p_{4}^{b p}\left(a-b p_{4}^{b p}\right)-w_{4}^{b p}\left(a-b p_{4}^{b p}-I_{3}^{b p}\right)-h I_{4}^{b p}+\pi_{r 5}^{b p} \\
\pi_{m 4}^{b p}=w_{4}^{b p}\left(a-b p_{4}^{b p}-I_{3}^{b p}\right)+\pi_{m 5}^{b p} \\
\pi_{r 3}^{b p}=p_{3}^{b p}\left(a-b p_{3}^{b p}\right)-w_{3}^{b p}\left(a-b p_{3}^{b p}-I_{2}^{b p}\right)-h\left(I_{3}^{b p}+I_{4}^{b p}\right)+\pi_{r 4}^{b p} \\
\pi_{m 3}^{b p}=w_{3}^{b p}\left(a-b p_{3}^{b p}-I_{2}^{b p}\right)+\pi_{m 4}^{b p} \\
\pi_{r 2}^{b p}=p_{2}^{b p}\left(a-b p_{2}^{b p}\right)-w_{2}^{b p}\left(a-b p_{2}^{b p}-I_{1}^{b p}\right)-h \sum_{t=2}^{4} I_{1}^{b p}+\pi_{r 3}^{b p} \\
\pi_{m 2}^{b p}=w_{2}^{b p}\left(a-b p_{2}^{b p}-I_{1}^{b p}\right)+\pi_{m 3}^{b p} \\
\pi_{r 1}^{b p}=p_{1}^{b p}\left(a-b p_{1}^{b p}\right)-w_{1}^{b p}\left(a-b p_{1}^{b p}+\sum_{t=1}^{4} I_{1}^{b p}\right)-\sum_{t=1}^{b} I_{1}^{b p}+\pi_{r 2}^{b p} \\
\pi_{m 1}^{b p}=w_{1}^{b p}\left(a-b p_{1}^{b p}+\sum_{t=1}^{4} I_{1}^{b p}\right)+\pi_{m 2}^{b p}
\end{gathered}
$$

The optimal solution for the retailer fifth-period optimization problem is obtained by solving $\frac{d \pi_{r 5}^{b p}}{d p_{5}^{b p}}=0$. On simplification, we have $p_{5}^{b p}=\frac{a+b w_{5}^{b p}}{2 b}$. The optimal solution for the supplier fifth-period optimization problem is obtained by solving $\frac{\partial \pi_{m 5}^{b p}}{\partial w_{5}^{b p}}=0$. On simplification, one can obtain $w_{5}^{b p}=\frac{a-2 I_{4}^{b p}}{2 b}$. The profit function 
for the retailer and supplier in fifth-period are concave because $\frac{d^{2} \pi_{r 5}^{s i}}{d p_{5}^{b^{2}}}=-2 b<0$ and $\frac{d^{2} \pi_{m 5}^{b p}}{d w_{5}^{b b^{2}}}=-b<0$, respectively. Similar to previous subsection, the profit function for the retailer in first-period is obtained as follows:

$$
\begin{gathered}
\pi_{r 1}^{b p}=\frac{a^{2}-3 I_{1}^{b p 2}+3 a\left(I_{1}^{b p}+I_{2}^{b p}+I_{3}^{b p}+I_{4}^{b p}\right)-4 b h\left(I_{2}^{b p}+2 I_{3}^{b p}+3 I_{4}^{b p}\right)-3\left(I_{2}^{b p^{2}}+I_{3}^{b p}+I_{4}^{b p 2}\right)}{4 b} \\
+\left(p_{1}^{b p}-w_{1}^{b p}\right)\left(a-b p_{1}^{b p}\right)-\left(I_{1}^{b p}+I_{2}^{b p}+I_{3}^{b p}+I_{4}^{b p}\right) w_{1}^{b p}-h\left(I_{1}^{b p}+I_{2}^{b p}+I_{3}^{b p}+I_{4}^{b p}\right)
\end{gathered}
$$

Optimal solution for the retailer first-period optimization problem is obtained by solving $\frac{\partial \pi_{r 1}^{b p}}{\partial r_{1}^{b p}}=0 ; \frac{\partial \pi_{r 1}^{b p}}{\partial I_{1}^{b p}}=0 ; \frac{\partial \pi_{r 1}^{b p}}{\partial I_{2}^{b p}}=0 ; \frac{\partial \pi_{r 1}^{b p}}{\partial I_{3}^{b p}}=0$ and $\frac{\partial \pi_{r 1}^{b p}}{\partial I_{4}^{b p}}=0$, simultaneously. After solving, following solution is obtained: $p_{1}^{b p}=\frac{a+b w_{1}^{b p}}{2 b} ; I_{1}^{b p}=\frac{3 a-4 b\left(h+w_{1}^{b p}\right)}{6}$; $I_{2}^{b p}=\frac{3 a-4 b\left(2 h+w_{1}^{b p}\right)}{6} ; I_{3}^{b p}=\frac{3 a-4 b\left(3 h+w_{1}^{b p}\right)}{6} ; I_{4}^{b p}=\frac{3 a-4 b\left(4 h+w_{1}^{b p}\right)}{6}$.

We compute the following Hessian matrix to check concavity:

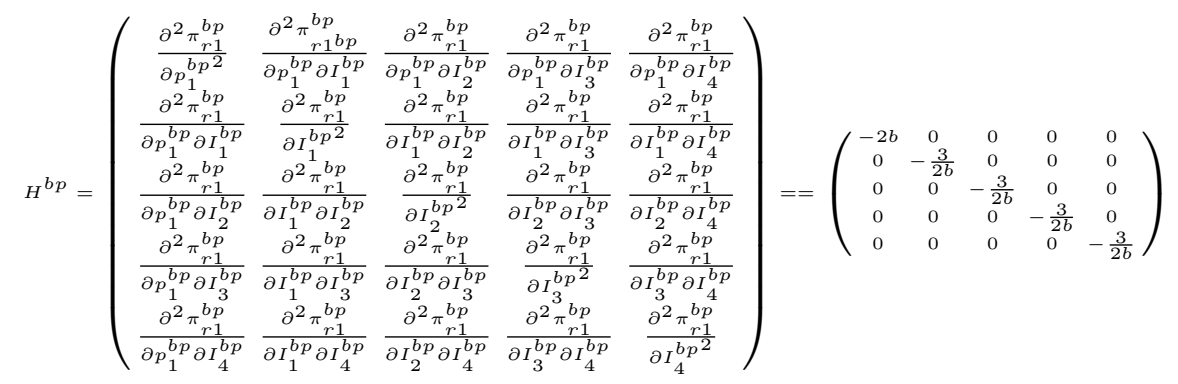

The values of principal minors are $\Delta_{1}=-2 b<0 ; \Delta_{2}=3>0 ; \Delta_{3}=-\frac{9}{2 b}<0$; $\Delta_{4}=\frac{27}{4 b^{2}}>0$ and $\Delta_{5}=-\frac{81}{8 b^{3}}<0$, i.e. profit function for the retailer is concave. Substituting the optimal response for the retailer, the profit function for the supplier in first-period is obtained as $\pi_{m 1}^{b p}=\frac{45 a w_{1}^{b p}+b\left(120 h^{2}-40 h w_{1}^{b p}-41 w_{1}^{b p^{2}}\right)}{18}$ and the corresponding wholesale price is $w_{1}^{b p}=\frac{5(9 a-8 b h)}{82 b}$. By using back substitution, one can obtain the following optimal solutions:

$$
\begin{aligned}
& w_{2}^{b p}=\frac{15 a+14 b h}{41 b} w_{3}^{b p}=\frac{45 a+124 b h}{123 b} w_{4}^{b p}=\frac{45 a b+206 b h}{123 b} w_{5}^{b p}=\frac{3(5 a+32 b h)}{41 b} \\
& p_{1}^{b p}=\frac{127 a-40 b h}{164 b} p_{2}^{b p}=\frac{7(4 a+b h)}{41 b} p_{3}^{b p}=\frac{2(42 a+31 b h)}{123 b} p_{4}^{b p}=\underline{84 a+103 b h} p_{5}^{b p}=\underline{4(7 a+12 b h)} \\
& I_{1}^{16 p}=\frac{11 a-28 b h}{82 b} I_{2}^{41 b}=\frac{33 a-248 b h}{246} I_{3}^{12 b}=\frac{33 a-412 b h}{246} I_{4}^{b p}=\frac{11 a-192 b h}{82} \\
& \pi_{r 5}^{b p}=\frac{503 a^{2}-4320 a b h-13824 b^{2} h^{2}}{3362 b} \pi_{m 5}^{b p}=\frac{2(6 a+29 b h)^{2}}{1089 b} \\
& \pi_{r 4}^{b p}=\frac{3018 a^{2}-23583 a b h-39074 b^{2} h^{2}}{10086 b} \pi_{m 4}^{b p}=\frac{5\left(405 a^{2}+4446 a b h+12538 b^{2} h^{2}\right)}{15129 b} \\
& \pi_{r 3}^{b p}=\frac{4527 a^{2}-31869 a b h-6254 b^{2} h^{2}}{10086 b} \pi_{m 3}^{b p}=\frac{6075 a^{2}+55620 a b h+140756 b^{2} h^{2}}{30258 b} \\
& \pi_{r 2}^{b p}=\frac{3018 a^{2}-18909 a b h+21770 b^{2} h^{2}}{5043 b} \pi_{m 2}^{b p}=\frac{10\left(405 a^{2}+2970 a b h+7126 b^{2} h^{2}\right)}{15129 b} \\
& \pi_{r 1}^{b p}=\frac{5\left(5727 a^{2}-15648 a b h+114976 b^{2} h^{2}\right)}{80688 b} \pi_{m 1}^{b p}=\frac{5\left(405 a^{2}-720 a b h+4256 b^{2} h^{2}\right)}{2952}
\end{aligned}
$$

2.3 Benchmark model

In Scenario BM, the retailer does not maintain SI or procure products in bulk. The profit functions for the retailer and supplier in each selling period are $\pi_{r}^{b m}=\left(p^{b m}-w^{b m}\right)\left(a-b p^{b m}\right)$ and $\pi_{m}^{b m}=w^{b m}\left(a-b p^{b m}\right)$, respectively. One may obtain the optimal response function of the retailer by solving first order condition of optimization as $p\left(w^{b m}\right)=\frac{a+b w^{b m}}{2}$. Substituting optimal response, 
the supplier's profit function is obtained as follows, $\pi_{m}=\frac{w^{b m}\left(a-b w^{b m}\right)}{2}$ and the corresponding optimal wholesale price is $w^{b m}=\frac{a}{2 b}$. Based on the optimal decisions, the closed form profit functions can be obtained as, $\pi_{r}^{b m}=\frac{a^{2}}{16 b}$ and $\pi_{m}^{b m}=\frac{a^{2}}{8 b}$. Note that in absence of additional inventory, wholesale and retail prices remain uniform in each period.

\section{Managerial Implications}

Proposition 1. In procurement scenario BP,

(i) the retailer and supplier sets maximum retail and wholesale price in first selling period, respectively.

(ii) the retail and wholesale prices increases from the second selling period.

(iii) the amount of products distributed by the retailer decreases as the selling period progress.

proof. The retail and wholesale prices, and SI in Scenario BP satisfy the following relations:

$$
\begin{gathered}
p_{1}^{b p}-p_{2}^{b p}=\frac{15 a-68 b h}{164 b}>0 \text { and } p_{2}^{b p}-p_{3}^{b p}=p_{3}^{b p}-p_{4}^{b p}=p_{4}^{b p}-p_{5}^{b p}=-\frac{h}{3}<0 \\
w_{1}^{b p}-w_{2}^{b p}=\frac{15 a-68 b h}{82 b}>0 \text { and } w_{2}^{b p}-w_{2}^{b p}=w_{3}^{b p}-w_{4}^{b p}=w_{4}^{b p}-w_{5}^{b p}=-\frac{2 h}{3}<0 \\
I_{1}^{b p}-I_{2}^{b p}=I_{2}^{b p}-I_{3}^{b p}=\frac{2 b h}{3}>0
\end{gathered}
$$

The above inequalities ensures proof.

Proposition 2. In procurement scenario WSI,

(i) the retailer and supplier sets maximum retail and wholesale price in first selling period, respectively.

(ii) the retail and wholesale prices decreases from the second selling period.

proof. The retail and wholesale prices, and SI in Scenario WSI:

$$
\begin{gathered}
p_{1}^{w s i}-p_{2}^{w s i}=\frac{0.0620142 a-0.6986787 b h}{b}>0, p_{2}^{w s i}-p_{3}^{w s i}=\frac{0.053645 a-0.444472 b h}{b}>0, \\
p_{3}^{w s i}-p_{4}^{w s i}=\frac{0.046382 a-0.206451 b h}{b}>0, p_{4}^{w s i}-p_{5}^{w s i}=\frac{0.04044 a+0.02515 h}{b}>0 \\
w_{1}^{w s i}-w_{2}^{w s i}=\frac{0.12402847 a-1.397357 b h}{b}>0, w_{2}^{w s i}-w_{3}^{w s i}=\frac{0.1072902 a-0.888943 b h}{b}>0 \\
w_{3}^{w s i}-w_{4}^{w s i}=\frac{0.092764 a-0.41290 b h}{b}>0, w_{4}^{w s i}-w_{5}^{w s i}=\frac{0.080871 a+0.05029 b h}{b}>0
\end{gathered}
$$

The above inequalities ensures proof.

\section{Proposition 3.}

(i) The retailer decision to maintain SI always outperforms the single period procurement decision if $h \in\left[\frac{0.0591229 a}{b}, \frac{0.125072 a}{b}\right]$

(ii) Supply chain member receives higher profits in procurement scenarios under BP compared to BM.

proof. The following relations ensure that the average profits of the supplier always greater compere to the profit earns by the supplier in Scenario BM:

$\pi_{m 1}^{w s i} / 5-\pi_{m}^{b m}=\frac{0.016674272 a^{2}-0.27416633 a h b+1.2414495 b^{2} h^{2}}{b}>0$

$\pi_{m 1}^{b p} / 5-\pi_{m}^{b m}=\frac{9 a^{2}-180 a h b+1064 b^{2} h^{2}}{738 b}=\frac{9(a-10 b h)^{2}+164 b^{2} h^{2}}{738 b}>0$

Similarly, the difference of average profits obtain under different scenarios with profits obtain in Scenario BM are

$\pi_{r 1}^{w s i} / 5-\pi_{r}^{b m}=\frac{0.0100956 a^{2}-0.251475 a b h+1.36527 b^{2} h^{2}}{b}$ if $h \in\left[\frac{0.0591229 a}{b}, \frac{0.125072 a}{b}\right]$

$\pi_{r 1}^{b p} / 5-\pi_{r}^{b m}=\frac{171 a^{2}-3912 a b h+28744 b^{2} h^{2}}{20172 b}>0$

The above inequalities ensures proof. 
The graphical representation of the profit functions of the retailer and supplier are shown in Figures 1a and 1b.

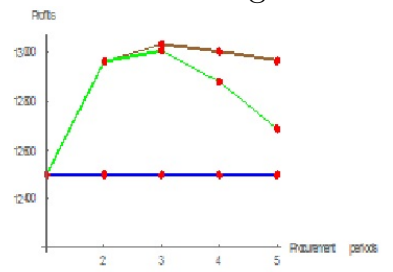

Fig 1a. Average profits of the retailer $\mathrm{a}=200, \mathrm{~b}=0.2$, and $\mathrm{h}=50$ Scenario $\mathrm{BP}$ (oreen

Figures $1 \mathrm{a}$ and $1 \mathrm{~b}$ demonstrate the profits of the supply chain members if the retailer makes procurement planning for five consecutive cycle. It is found that Scenario BM is always outperformed by both scenarios BP and SI. It is found that the profit functions of the retailer does not demonstrate a cumulatively pattern. Due to additional procurement in the first selling period, the profit functions demonstrate that nature. However, one can not conclude with regards to the optimality of the procurement planning of the retailer.

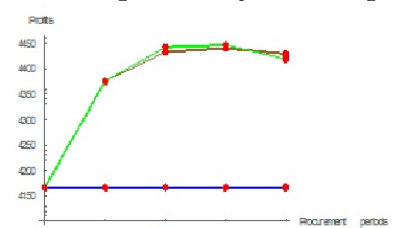

Fig 2a. Average profits of the retailer

Average profits of the retailer Fig $2 \mathrm{~b}$. Average profits of the manufacturer
$\mathrm{a}=200, \mathrm{~b}=0.6$, and $\mathrm{h}=10$ Scenario BP (green), WSI (Brown), and BM (blue)

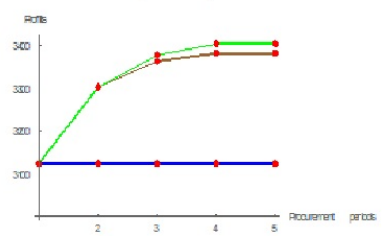

Fig 3a. Average profits of the retailer $\mathrm{a}=200, \mathrm{~b}=0.8$, and $\mathrm{h}=5$ Scenario BP (green), WSI (Brown), and BM (blue)
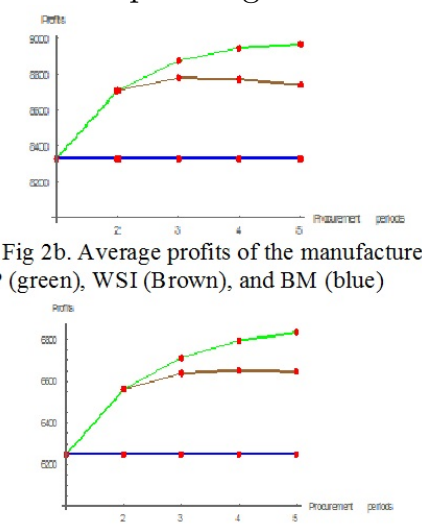

Fig 3 b. Average profits of the manufacturer

Price elasticity and product holding cost are two extremely important factors affecting procurement decision and overall profitability. Price-elasticity is a critical factor ([10], [11]) influencing the demand. Therefore, more analytical investigations are required to obtain concrete conclusion.

\section{Conclusion}

The pricing and procurement decisions in a supplier-retailer five-period supply chain is explored in this study. Under price sensitive demand, impact of three procurement decisions are analyzed and corresponding Stackelberg equilibriums are compared. The comparison among equilibrium outcomes in perspective of profits of each supply chain members demonstrate how the procurement decision is influencing the overall preference of the supply chain members. In contrast to 
Anand et al. [1], it is found that the build-up SI is not always profitable for the retailer, and manufacturer also. Price-elasticity and holding cost of the retailer are critical factors effecting procurement decision.

The present analysis can be extended to include several important features. For the analytical tractability, we consider five consecutive selling period. In future, one can extend the generalized version of the proposed model. One can also consider the effect of product deterioration or imperfect quality item.

\section{References}

1. Anand, K., Anupindi, R., Bassok, Y.: Strategic inventories in vertical contracts. Management Science 54(10), 1792-1804 (2018)

2. Arya, A., Frimor, H., Mittendorf, B.: Decentralized procurement in light of strategic inventories. Management Science 61(3), 578-585 (2014)

3. Arya, A., Mittendorf, B.: Managing strategic inventories via manufacturer-toconsumer rebates. Management Science 59(4), 813-818 (2013)

4. Nielsen, P., Nielsen, I., Steger-Jensen, K.: Analyzing and evaluating product demand interdependencies. Computers in Industry, 61 (9), 869-876 (2010) Eriksen, P.S., Nielsen, P.: Order quantity distributions: Estimating an adequate aggregation horizon. Management and Production Engineering Review, 7(3), 39-48 (2016)

5. Hartwig, R., Inderfurth, K., Sadrieh, A., Voigt, G.: Strategic inventory and supply chain behavior. Production and Operations Management 24(8), 1329-1345 (2015)

6. Mantin, B., Jiang, L.: Strategic inventories with quality deterioration. European Journal of Operational Research 258(1), 155-164 (2017)

7. Moon, I., Dey, K., Saha, S.: Strategic inventory: manufacturer vs. retailer investment. Transportation Research Part E: Logistics and Transportation Review 109(C), 63-82 (2018)

8. Michna, Z., Nielsen, P., Nielsen, I.E.: The impact of stochastic lead times on the bullwhip effect - a theoretical insight. Production and Manufacturing Research, DOI: $10.1080 / 21693277.2018 .1484822$ (2018)

9. Sitek, P., Wikarek, J., Nielsen, P.: A constraint-driven approach to food supply chain management. Industrial Management and Data Systems, 117 (9), 2115-2138 (2017)

10. Walters, R., Bommer, W.: Measuring the impact of product and promotion-related factors on product category price elasticities. Journal of Business Research, 36(3), 203-216 (1996)

11. Huang, A., Dawes, J., Lockshin, L., Greenacre, L. Consumer response to price changes in higher-priced brands Journal of Retailing and Consumer Services, 39, 1-10 (2017) 